\title{
Estrogen Blocks M-CSF Gene Expression and Osteoclast Formation by Regulating Phosphorylation of Egr-1 and Its Interaction with Sp-1
}

\author{
Sunil Srivastava, ${ }^{\star}$ M. Neale Weitzmann, ${ }^{\star}$ Robert B. Kimble, ${ }^{\star}$ Monica Rizzo, ${ }^{\ddagger}$ Michael Zahner, ${ }^{\star}$ Jeffrey Milbrandt, ${ }^{\S}$ \\ F. Patrick Ross, $\$$ and Roberto Pacifici* \\ $*$ Division of Bone and Mineral Diseases, ${ }^{\ddagger}$ Department of Surgery, and ${ }^{\S}$ Department of Pathology, Washington University School of \\ Medicine, and Barnes-Jewish Hospital, St. Louis, Missouri 63110
}

\begin{abstract}
Central to the pathogenesis of osteoporosis is the ability of estrogen deficiency to increase osteoclast formation by enhancing stromal cell production of the osteoclastogenic cytokine macrophage colony-stimulating factor (M-CSF). We report that stromal cells from ovariectomized mice exhibit increased casein kinase II-dependent phosphorylation of the nuclear protein Egr-1. Phosphorylated Egr-1 binds less avidly to the transcriptional activator Sp-1 and the resulting higher levels of free $\mathrm{Sp}-1$ stimulate transactivation of the M-CSF gene. Estrogen replacement fails to block M-CSF mRNA expression and osteoclast formation in ovariectomized mice lacking Egr-1, confirming the critical role played by this transcription factor in mediating the antiosteoclastogenic effects of estrogen. Thus, by downregulating formation of a novel Egr-1/Sp-1 complex in stromal cells, estrogen deficiency results in enhanced levels of free Sp-1 and increased M-CSF gene expression and osteoclast formation. (J. Clin. Invest. 1998. 102:1850-1859.) Key words: macrophage colony-stimulating factor - estrogen - osteoclasts $\cdot$ Egr-1 $\cdot$ Sp-1
\end{abstract}

\section{Introduction}

It is now recognized that one of the main mechanisms by which estrogen (E2) ${ }^{1}$ deficiency causes bone loss is by stimulating osteoclast (OC) formation (1), a process facilitated by bone marrow stromal cells (SC). SC provide a physical support for nascent $\mathrm{OC}$ and produce soluble and membrane-associated factors which regulate the proliferation and/or the differentia-

Address correspondence to Roberto Pacifici, M.D., Division of Bone and Mineral Diseases, Barnes-Jewish Hospital, North Campus, 216 S. Kingshighway, St. Louis, MO 63110. Phone: 314-454-8407; FAX: 314454-5047; E-mail: Pacifici@imgate.wustl.edu

Received for publication 14 July 1998 and accepted in revised form 28 September 1998.

1. Abbreviations used in this paper: CAT, chloramphenicol acetyltransferase; CIAP, calf intestinal alkaline phosphatase; CKII, casein kinase II; E2, estrogen; EMSA, electrophoretic mobility shift assay; IL-1ra, IL-1 receptor antagonist; IP, immunoprecipitation; KO, knockout; M-CSF, macrophage colony-stimulating factor; OC, osteoclast(s); ovx, ovariectomized; PKC, protein kinase C; r, recombinant; $\mathrm{SC}$, stromal cell(s); TNFbp, TNF binding protein; TRAP, tartrateresistant acid phosphatase; WT, wild-type.

J. Clin. Invest.

(C) The American Society for Clinical Investigation, Inc. 0021-9738/98/11/1850/10 \$2.00

Volume 102, Number 10, November 1998, 1850-1859

http://www.jci.org tion of OC precursors (2). Among these factors is macrophage colony-stimulating factor (M-CSF), a cytokine which plays a critical role in murine osteoclastogenesis, as demonstrated by the capacity of anti-M-CSF antibodies to block OC formation in vitro (3) and by the ability of M-CSF replacement to cure osteopetrosis in $o p / o p$ mice, a strain characterized by the production of defective M-CSF (4). In humans, M-CSF induces OC formation, stimulates survival and chemotactic behavior of isolated $\mathrm{OC}$, and is essential for conferring the capacity of maturing OC to resorb bone (5). SC production of M-CSF is induced by IL-1 and TNF $(6,7)$, cytokines produced mainly by bone marrow mononuclear cells and recognized for their ability to promote OC formation and bone resorption (8).

In a recent study we determined that one of the consequences of the decreased bone marrow levels of IL-1 and TNF induced by $\mathrm{E} 2$ is the formation of SC which possess low osteoclastogenic activity and respond to acute IL-1 and TNF stimulation by producing low levels of M-CSF. Conversely, SC differentiating in the absence of E2 (and the resulting increased bone marrow levels of IL-1 and TNF) exhibit enhanced M-CSF production in response to acute stimulation with IL-1 and TNF, and increased osteoclastogenic activity (9). The demonstration that E2 modulates SC production of M-CSF by regulating bone marrow IL-1 and TNF levels, and the resulting differentiation of SC precursors, provide an explanation for increased bone resorption characteristic of the postmenopausal state. However, our findings raise the question of the mechanism by which SC from E2-deficient mice produce increased levels of $\mathrm{M}-\mathrm{CSF}$ in response to acute IL-1 and TNF stimulation.

The regulatory region of the murine $\mathrm{M}-\mathrm{CSF}$ gene contains overlapping consensus sequences for members of the Egr and Sp families (10). Among the members of these families which have been reported to bind to the Egr and Sp sites are Egr-1 (also known as NGFI-A, Zif 268, Krox24, and TIS8) (11, 12), the general transcription activator Sp-1 (13), and the related factor Sp-3 (14). Egr-1 is a nuclear phosphoprotein that is rapidly and transiently induced by serum and growth factors and binds to a specific DNA sequence (5'-GCGGGGGCG-3') in a zinc-dependent manner (11). The action of Egr-1 on gene transcription is regulated by its phosphorylation (11). Egr-1 is phosphorylated by casein kinase II (CKII) (15), an inducible kinase present in both the cytoplasm and nucleus of eukaryotic cells and one which phosphorylates proteins at serine and threonine residues immersed in acidic sequences (16). Sp-1 is a general transcription factor, constitutively expressed in most cells, that serves to activate gene transcription (13), whereas the related factor $\mathrm{Sp}-3$ is a repressor of $\mathrm{Sp}-1$-induced transcription (14).

The presence of binding sites for Egr-1 and Sp-1 in the murine M-CSF promoter suggested that the mechanism which allows mature SC from E2-deficient mice to produce increased amounts of M-CSF involves altered Sp and/or Egr transcrip- 
tion factors binding to the M-CSF promoter. This hypothesis was investigated in the current study, which was carried out in primary cultures of SC purified from the bone marrow of sham-operated and ovariectomized (ovx) mice. Herein, we report that IL-1 and TNF stimulated SC from ovx mice are characterized by enhanced CKII-induced Egr-1 phosphorylation, a posttranslational modification which leads to decreased formation of an Egr-1/Sp-1 complex. The suppressed association of Egr-1 and Sp-1, in the face of unchanged levels of total Sp-1, results in increased levels of free Sp-1 available for binding to the M-CSF promoter, an event culminating in increased M-CSF gene expression. The significance of these findings in vivo was confirmed by the demonstration that E2 fails to block M-CSF mRNA expression and OC formation in bone marrow cell cultures from ovx Egr-1 knockout (KO) mice.

\section{Methods}

All animal procedures were approved by the Animal Care and Use Committee of Barnes-Jewish Hospital. Unless otherwise specified, reagents and media were from Sigma Chemical Co. (St. Louis, MO).

Study protocol and SC preparation. $\mathrm{C} 3 \mathrm{H} / \mathrm{Hen}$ mice (The Jackson Laboratory, Bar Harbor, ME) 5 wk of age were ovx or sham-operated, as described previously $(9,17)$. ovx mice were either left untreated or treated with $17 \beta$ estradiol $(0.16 \mu \mathrm{g} / \mathrm{d}$, the lowest dose which maintains a normal uterine weight) for $2 \mathrm{wk}$ using slow release subcutaneous pellets (Innovative Research of America, Toledo, OH), implanted in a nuchal subcutaneous pocket. For some experiments, ovx mice were treated with the IL-1 inhibitor, IL-1 receptor antagonist (IL-1ra) $(25 \mathrm{mg} / \mathrm{kg}$ of body wt per day), plus the TNF inhibitor, TNF binding protein (TNFbp) $(1 \mathrm{mg} / \mathrm{kg}$ of body wt per day), as described $(9,17)$. IL-1ra and TNFbp were kindly provided by Amgen Inc. (Thousand Oaks, CA). 2 wk after surgery mice were killed, femora and tibiae were excised, and bone marrow was flushed with icecold $\alpha$-MEM and used to purify SC, as described previously (9).

To determine if E2 blocks M-CSF production in vivo via an Egr1-mediated mechanism, experiments were conducted using Egr-1 KO mice (18). These mice were generated by using an Egr-1 construct from BALB/c mouse genomic library and C57B1/6 mice. To ensure that $\mathrm{KO}$ and wild-type (WT) mice had the same genetic background, the original heterozygous $($ Egr- $1+/-)$ mouse was back-bred for 10 generations into C57B1/6 mice. Homozygous (Egr-1-/- and Egr-1+/+) mice were then generated by cross-breeding male and female mice, each heterozygous for Egr-1.

These mice have E2 levels equal to those of WT controls. However, they have frequent anovulatory cycles due to progesterone deficiency (19). To eliminate this potential confounder, Egr-1 KO mice and age-matched WT littermates were ovx at $5 \mathrm{wk}$ of age. Half of the $\mathrm{KO}$ and half of the control littermates were treated with $17 \beta$ estradiol for $2 \mathrm{wk}$ while the remaining mice were left untreated. At the end of the treatment period, all mice were killed and bone marrow was harvested and used to purify SC.

Bone marrow cell cultures and OC characterization. Bone marrow cells from Egr-1 KO and WT littermates were cultured for $7 \mathrm{~d}$ with 10 $\mathrm{nM} 1,25(\mathrm{OH})_{2} \mathrm{D}_{3}$ in multiwell plates to induce OC formation (9). Cells were then fixed and stained for tartrate-resistant acid phosphatase (TRAP). TRAP-positive cells with three or more nuclei were counted as OC-like cells. Expression of calcitonin receptors was also assessed by autoradiography, as described previously (17). More than $98 \%$ of the TRAP-positive multinucleated cells formed in the bone marrow cultures showed specific binding of labeled calcitonin. Therefore, we regarded the TRAP-positive multinucleated cells formed in the bone marrow cultures as authentic OC.

SC transient transfections and chloramphenicol acetyltransferase (CAT) assays. Transient transfections were performed using M-CSF promoter-deletion constructs, coupled to a CAT reporter gene, a kind gift of Dr. M.A. Harrington (University of Indiana, Bloomington, IN). Transfections were carried out using $4 \mu \mathrm{g}$ of the appropriate $\mathrm{M}$-CSF reporter construct, $1 \mu \mathrm{g}$ of $\beta$-galactosidase expression vector coupled to a CMV promoter mixed with $12 \mu \mathrm{l}$ of lipofectamine reagent (GIBCO BRL, Gaithersburg, MD). The cells were washed twice with PBS, incubated in $\alpha$ MEM, supplemented with $10 \%$ FBS, $10 \%$ horse serum, and stimulated with IL-1 and TNF $(10 \mathrm{ng} / \mathrm{ml}$ of each). Cells were harvested after $24 \mathrm{~h}$ and lysed by three freeze-thaw cycles in $200 \mu \mathrm{l}$ of $250 \mathrm{mM}$ Tris- $\mathrm{HCl}, \mathrm{pH} \mathrm{7.5}$, as described (20). CAT and $\beta$-galactosidase activities were measured as described $(21,22)$, respectively. Results are expressed as normalized CAT activity after correction for transfection efficiency using the cotransfected $\beta$-galactosidase control for each well.

Transient transfection of SL-2 cells. SL-2 cells, a line lacking endogenous Sp-1 and Sp-3 factors (23), were grown in Schneider's media supplemented with $10 \% \mathrm{FBS}$ at $25^{\circ} \mathrm{C}$ and transiently transfected using the calcium phosphate technique (24). The expression vectors Egr-1, Sp-1, and Sp-3 (2 $\mu$ g of each) were cotransfected along with $\beta$-galactosidase expression vector $(1 \mu \mathrm{g})$ and M-CSF/CAT $(2 \mu \mathrm{g})$ reporter construct (construct 1) per well into SL-2 cells. Differences in plasmid concentration were equalized using pUC plasmid. Cells were harvested after an overnight incubation and cell extracts were assayed for CAT and $\beta$-galactosidase activity as described above.

Extraction of nuclear protein and electrophoretic mobility shift assays (EMSAs). Purified SC grown to confluence were incubated in $\alpha$ MEM supplemented with $0.2 \%$ FBS for $3 \mathrm{~h}$, and stimulated for $1 \mathrm{~h}$ with IL-1 and TNF (10 ng/ml each). Nuclear extracts were prepared as described (25). Protein concentration was determined by the micro bicinchoninic acid assay.

EMSAs were performed as described (26) using the following oligonucleotide: (upper strand $=$ 5'CTCGAGAAGGGCGGGGGAGGGCGGTGG3') containing a segment of the M-CSF promoter spanning regions -283 to $-257 \mathrm{bp}$. Bases in bold represent the Sp-1/ Sp-3 binding region with the Egr-1 binding site underlined.

Western blot and immunoprecipitation (IP) studies. Western blots were conducted as described (27) using anti-Sp-1 or anti-Egr-1 antibodies (Santa Cruz Biotechnology, Santa Cruz, CA). Proteins were visualized by ECL chemiluminescence (Amersham, Arlington Heights, IL). To determine if Egr-1 binds to Sp-1 via direct protein-protein interaction, IP reactions were performed as described (15). Western blots were performed on IP complexes using anti-Sp-1 antibody to detect the presence of Sp-1 in the protein complex.

Yeast 2-hybrid assay. Egr-1 and Sp-1 cDNAs were subcloned into yeast 2-hybrid vectors pACT2 and pGBT9, respectively, such that fusion proteins were generated in vivo with the GAL4 activating domain coupled to Egr-1 and the GAL4 DNA-binding domain coupled to Sp-1. Each fusion vector was transfected individually (as a negative control) and in combination into each of two different reporter yeast strains (SFY526 and HF7c). SFY526 carries a lacZ reporter driven by a GAL1 promoter sequence. Positive protein-protein interaction between Egr-1 and Sp-1 is demonstrated by means of blue color formation in the presence of X-gal. The yeast strain HF7c is deficient in histidine production and carries histidine growth selection as a result of a His 3 gene coupled to a GAL1 promoter sequence, activated by positive interaction between Sp-1 and Egr-1. In addition, this strain also carries a lacZ color reporter coupled to a $\mathrm{CYC} 1$ promoter, responsive to GAL4 elements. This provides an independent confirmation of positive Sp-1/Egr-1 interaction signaled by means of blue color development after incubation with X-gal. Additional positive and negative controls were used.

Transformation of 2-hybrid clones into yeast hosts. Competent yeast cells were prepared using the lithium acetate method and transfected according to the manufacturer's instructions (Promega, Madison, WI). Transformed cells were spread onto agar plates containing the appropriate synthetic dropout selection markers (tryptophan and leucine for SFY526 and tryptophan, leucine, and histidine for HF7c). For HF7c transformants, growth in the absence of histidine was considered positive for protein interaction. In addition, both strains were as- 
sessed for $\beta$-galactosidase activity, by colony lift according to the protocol guide (Promega), as independent evidence of Egr-1/Sp-1 interaction. pVA3 + pTD1 and pLAM5' + pTD1 were used as positive and negative controls, respectively.

Egr-1 phosphorylation and CKII activity assays. Egr-1 phosphorylation and CKII activity were assessed as described in references 28 and 29, respectively. For some experiments, heparin was added to the assay buffer at a final concentration of $1 \mu \mathrm{g} / \mathrm{ml}$. In some experiments $\left[\gamma^{32} \mathrm{P}\right] \mathrm{GTP}$ was used in place of $\left[\gamma^{-32} \mathrm{P}\right] \mathrm{ATP}$. In these experiments, 0.5 $\mathrm{mM} \mathrm{MnCl} 2$ was substituted for $\mathrm{MgCl}_{2}$ in the assay buffer. To measure CKII activity in the absence of additional nuclear material, nuclear protein was IP with CKII $\alpha$ antibody before assay.

RNase protection assay. M-CSF mRNA expression was quantitated in SC from Egr-1 KO mice and control littermates, by RNase protection assay. SC were stimulated with IL-1 and TNF for $4 \mathrm{~h}$ before assay. Total RNA was extracted as described (30). RNase protection assay was conducted using a RiboQuant ${ }^{\mathrm{TM}}$ KIT (PharMingen, San Diego, CA). M-CSF and GAPDH riboprobes were prepared by in vitro transcription (RiboQuant ${ }^{\mathrm{TM}}$ ) according to the manufacturer's instructions using templates provided in the kit.

Statistical analysis. Group mean values were compared by twotailed Student's $t$ test or one-way ANOVA as appropriate. Subsequent mean comparison tests were performed by Fisher protected LSD test.

\section{Results}

Sp-1, Sp-3, and Egr-1 regulate M-CSF gene expression. To identify the $c i s$-acting elements that mediate transcriptional activation of murine M-CSF by IL-1 and TNF, SC were transiently transfected with a series of M-CSF promoter deletion constructs linked to a CAT reporter gene, and then stimulated with IL-1 and TNF. Strong CAT activity was observed (Fig. $1 A$ ) in cells transfected with the $-627 \mathrm{nt}$ to $+174 \mathrm{nt}$ region of the M-CSF gene (construct 1). Deletion of the region $-627 \mathrm{nt}$ to $-509 \mathrm{nt}$ (construct 2) did not alter CAT activity. Conversely, deletion of the region from $-509 \mathrm{nt}$ to $-329 \mathrm{nt}$ (construct 3 ) resulted in a 2.2-fold increase of CAT activity, suggesting the presence of an inhibitory sequence. Cells transfected with construct 4 (spanning region $-152 \mathrm{nt}$ to $+174 \mathrm{nt}$ ), which lacks the overlapping consensus sequences ( $-273 \mathrm{nt}$ to $-265 \mathrm{nt})$ of transcription factors of the Sp and Egr families, exhibited a 4-fold inhibition of CAT activity compared with cells transfected with construct 3 , and a 2.5-fold inhibition compared with baseline. Deletion of additional promoter sequences (constructs 5 and 6) resulted in smaller changes in CAT activity. These data suggest that Sp and Egr gene products play an important role in regulating $\mathrm{M}-\mathrm{CSF}$ gene expression in murine SC.

To investigate the functional relevance of $\mathrm{Sp}-1, \mathrm{Sp}-3$, and Egr-1 in regulating M-CSF gene expression, Schneider SL-2 cells, a Drosophila melanogaster line lacking endogenous Sp $(14,31)$ and Egr factors (unpublished observations), were transiently cotransfected with M-CSF-CAT reporter plasmid (construct 1) and equal amounts of either Sp-1, Sp-3, or Egr-1 expression vectors. Both Egr-1 and Sp-3 expression vectors repressed the reporter construct (Fig. $1 B$ ). In contrast, cotransfection with M-CSF-CAT reporter construct and Sp-1 expression vector resulted in an $\sim 5$.0-fold activation of the reporter construct. The increase in CAT activity induced by Sp-1 was completely abolished by cotransfection with either Sp-3 or Egr-1 expression vectors. These data demonstrate that $\mathrm{Sp}-1$ is a potent inducer of M-CSF gene expression and that both Egr-1 and Sp-3 can reverse the stimulatory effects of Sp-1 on M-CSF gene expression.
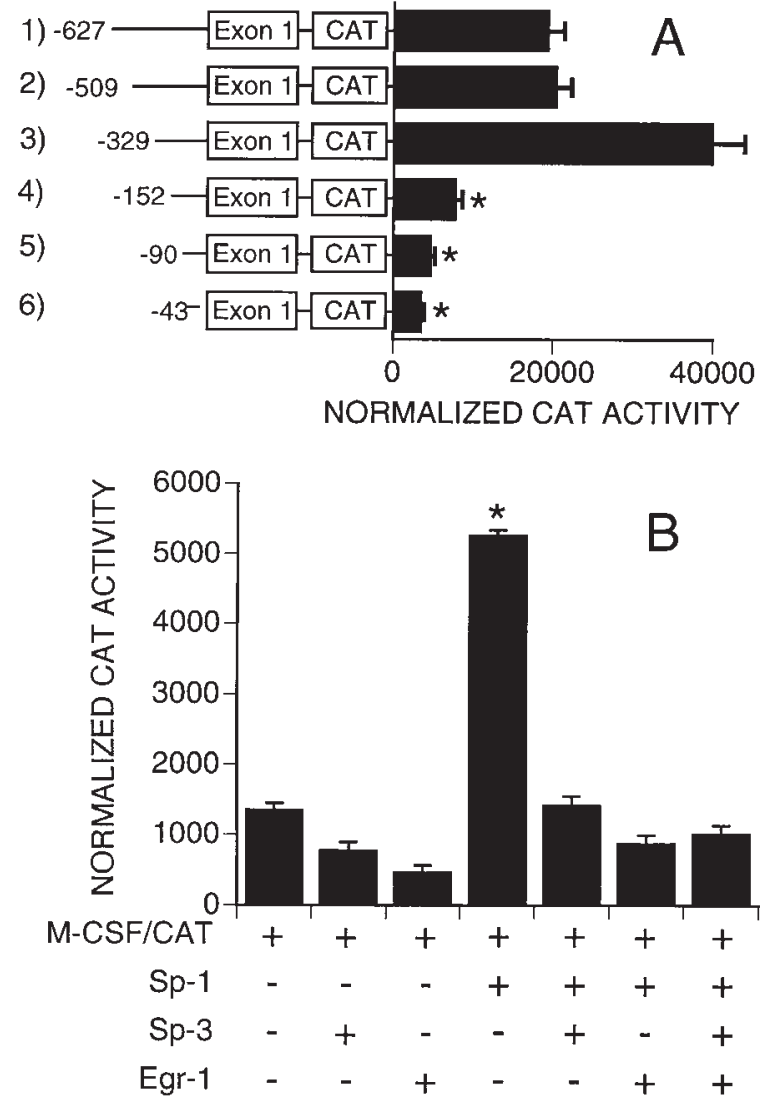

Figure 1. (A) Functional analysis of the M-CSF promoter in IL-1and TNF-stimulated SC. Constructs containing deletions of murine $\mathrm{M}-\mathrm{CSF}$ promoter sequences are shown schematically relative to construct 1 , which contains $-627 \mathrm{bp}$ of M-CSF 5 ' flanking sequence and the first M-CSF exon (+1 to +174). The Egr and Sp sites are contained in the -273 bp to -265 bp region. Exon 1 was cloned upstream of the CAT cDNA. The $5^{\prime}$ end point of each construct is shown at the left. The values represent the average $( \pm$ SEM) of three independent determinations. CAT activity was normalized to $\beta$-galactosidase activity to correct for variability in transfection efficiency and expressed as normalized CAT activity. ${ }^{*} P<0.05$ compared with construct 1. (B) Sp-3 and Egr-1 repress Sp-1-induced M-CSF gene expression in SL-2 Drosophila melanogaster cells transiently transfected with a M-CSF/CAT reporter gene construct (mean of three replicate experiments). SL-2 cells were transiently transfected with a M-CSF/CAT construct containing the $-627 \mathrm{bp}$ to $+174 \mathrm{bp}$ region of the M-CSF gene (construct 1) along with of Sp-1, Sp-3, and Egr-1 expression vectors. The cells were subsequently lysed and assayed for CAT and $\beta$-galactosidase activities as described in Methods. ${ }^{*} P<$ 0.05 compared with each of the other constructs.

Sp-1 and Sp-3 but not Egr-1 bind to the M-CSF promoter. To determine which members of the Egr and Sp families of transcription factors bind to the M-CSF promoter in SC, EMSAs were conducted by incubating nuclear extracts from IL-1- and TNF-stimulated SC with a radiolabeled oligonucleotide corresponding to the region of the M-CSF promoter ( $-283 \mathrm{nt}$ to $-257 \mathrm{nt}$ ) containing the Egr and Sp binding motifs. Two distinct DNA-protein complexes were detected (Fig. $2 A$, lane 1 ) in nuclear extracts prepared from SC harvested from control mice. Both complexes were specific, as they were competed by unlabeled oligonucleotide (lane 9). In contrast, neither complex was competed out by an unlabeled oligonucleotide which 
A

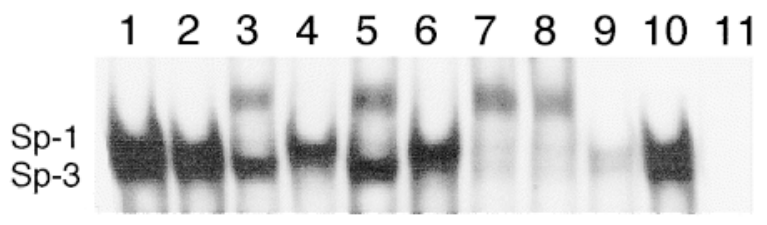

B

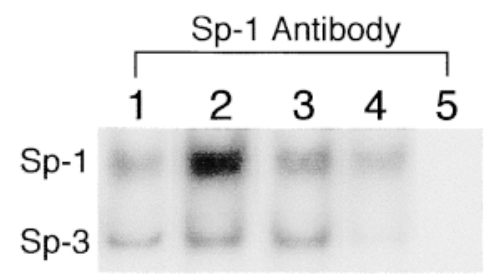

C
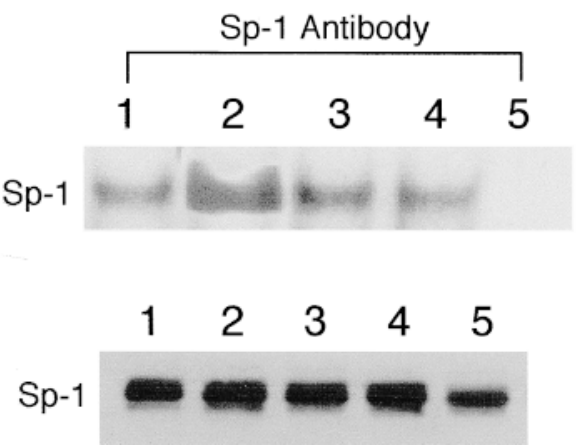

Figure 2. (A) Nuclear proteins binding to the Egr/Sp binding site of the M-CSF promoter are Sp-1 and Sp-3. Gel mobility shift assays were performed by incubating nuclear extracts of SC stimulated with IL-1 and TNF for $1 \mathrm{~h}$ with a 26-bp ${ }^{32} \mathrm{P}$-labeled probe containing the Egr/Sp binding site of the M-CSF promoter. Lane 1, SC nuclear extracts from control mice. Lanes $2-8$, SC nuclear extracts from control mice plus the following antibodies: lane 2, Egr-1 antiserum; lane 3, Sp-1 antiserum; lane 4, Sp-3 antiserum; lane 5, Egr-1 + Sp-1 antiserum; lane 6, Egr-1 + Sp-3 antiserum; lane 7, Sp-1 + Sp-3 antiserum; lane 8, Egr-1 + Sp-1 + Sp-3 antiserum. Lane 9, $80 \times$ unlabeled probe Lane 10, $80 \times$ unlabeled specific Egr-1 consensus sequence. Lane 11, probe only. Similar results were obtained in each of three replicate experiments. $(B)$ ovx increase Sp-1 binding to the Sp site of the $\mathrm{M}-\mathrm{CSF}$ promoter. A 26-bp ${ }^{32} \mathrm{P}$-labeled oligonucleotide containing the Egr/Sp binding site was incubated with nuclear extracts of IL-1and TNF-stimulated SC from sham-operated (lane 1), untreated ovx (lane 2), E2-treated ovx (lane 3), or IL-1ra + TNFbp-treated ovx mice (lane 4). Lane 5, probe only. These gel mobility shift assays were performed in the presence of anti-Sp-1 antiserum to resolve the Sp-1 and Sp-3 bands. Data shown are from one of four experiments. Densitometric analysis of the data from all four experiments revealed that Sp-1 binding was $2.5 \pm 0.5$-fold $(P<0.05)$ higher in SC from ovx mice than in those from E2-replete mice. $(C)$ ovx increases the binding of $\mathrm{Sp}-1$ to a consensus sequence specific for Sp transcription factors. A ${ }^{32} \mathrm{P}$-labeled probe corresponding to a consensus sequence which binds Sp but not Egr transcription factors was incubated with nuclear extracts of IL-1- and TNF-stimulated SC from sham-operated (lane 1), untreated ovx (lane 2), E2-treated ovx (lane 3), or IL-1ra + TNFbptreated ovx mice (lane 4). Lane 5, probe only. These gel mobility shift assays were performed in the presence of anti-Sp-1 antiserum to resolve the Sp-1 and Sp-3 bands. Data shown are from one of four experiments. Densitometric analysis of the data from all four experiments revealed that Sp-1 binding was 3.1 \pm 0.4 -fold $(P<0.05)$ higher in SC from ovx mice than in those from E2-replete mice. $(D)$ Western blot analysis of Sp-1 protein demonstrates that ovx does not increase Sp-1 levels in SC nuclei. Lane 1, sham-operated. Lane 2, untreated forms a specific complex with recombinant (r) Egr-1 but not with either $\mathrm{rSp}-1$ or $\mathrm{rSp}-3$. When antiserum directed against Sp-1 was included in these assays, the slower migrating band was supershifted (lane 3). Addition of antiserum against Sp-3 resulted in the disappearance of the faster migrating band (lane 4). The addition of both anti-Sp-1 and anti-Sp-3 antisera to the reaction mixture resulted (lane 7) in the supershift of the slower migrating band and the disappearance of the faster migrating band. In contrast, when antiserum directed against Egr-1 was included in these assays, there was no change in the pattern of shifted bands (lane 2). Similarly, the addition of anti-Egr-1, Sp-1, and Sp-3 antisera (lane 8) resulted in a migration pattern identical to that observed in the presence of antiSp-1 and anti-Sp-3 antisera alone (lane 7). Taken together, the data demonstrate that $\mathrm{Sp}-1$ gives rise to the upper complex and $\mathrm{Sp}-3$ to the lower one.

Ovariectomy increases the binding of $\mathrm{Sp}-1$ to the M-CSF promoter without altering the nuclear levels of $S p-1$. To test if increased M-CSF production, characteristic of SC formed in the bone marrow of E2-deficient mice, is the result of increased Sp-1 binding to the M-CSF promoter, we investigated if the interaction of Sp-1 and/or Sp-3 with DNA is modulated by ovx and E2 replacement. Moreover, since E2 deficiency induces the formation of "high" M-CSF producing SC by increasing marrow monocyte production of IL-1 and TNF (9), we also investigated whether in vivo treatment of ovx mice with the IL-1 inhibitor, IL-1ra, and the TNF inhibitor, TNFbp, regulates Sp-1 binding. SC nuclear extracts were prepared and incubated with radiolabeled oligonucleotide corresponding to the overlapping Egr and Sp site ( $-283 \mathrm{nt}$ to $-257 \mathrm{nt})$. AntiSp-1 antibody was added to all samples to resolve the Sp-1 and Sp-3 bands (Fig. 2 B). Consistent with our earlier findings, Sp-1 antibody supershifted the slower migrating band and separated the Sp- 1 and the Sp-3 bands in all groups. In each of four experiments we found that nuclear extracts from untreated ovx mice (lane 2) had higher Sp-1 binding activity than those from both sham-operated (lane 1) and ovx mice treated with either E2 (lane 3) or IL-1ra and TNFbp (lane 4). Quantification of Sp-1 binding by densitometric analysis of the data from all four experiments demonstrated that ovx increased Sp-1 binding 2.5 \pm 0.5 -fold over SC from untreated sham-operated mice $(P<0.05)$. Attesting to specificity, nuclear extracts from ovx mice had a similar Sp-3 binding activity as those from E2treated ovx mice, thus demonstrating that ovx increases Sp-1 binding independently of Sp-3. Taken together, these data demonstrate that E2 deficiency results, via an IL-1- and TNFdependent mechanism, in the formation of a SC population which responds to cytokine stimulation by increased Sp-1 binding to the M-CSF promoter.

To exclude the possibility that competition between Egr-1 and $\mathrm{Sp}-1$ contributes to the regulation of $\mathrm{Sp}-1$ binding to DNA, we used a radiolabeled oligonucleotide which binds Sp-1 but not Egr-1. These EMSAs revealed (Fig. $2 C$ ) that nuclear extracts from ovx mice have a higher $(3.1 \pm 0.4$-fold, $P<0.05)$ Sp-1 binding activity (lane 2 ) than nuclear extracts from either sham-operated (lane 1), E2-treated ovx mice (lane 3), or IL1ra + TNFbp-treated ovx mice (lane 4 ). These findings dem-

ovx. Lane 3, E2-treated ovx. Lane 4, IL-1ra + TNFbp-treated ovx. Lane 5, Sp-1 control. Representative data from one of three replicate experiments. 
onstrate that ovx increases Sp-1 binding to the M-CSF promoter by a mechanism other than direct competition with Egr-1 for DNA binding.

Western blot analysis of nuclear extracts demonstrated equal expression of Sp-1 protein in SC from ovx and E2replete mice (Fig. $2 D$ ), thus suggesting that ovx increases Sp-1 binding to the M-CSF promoter by either enhancing its affinity for DNA or the levels of free Sp-1 available for binding.

ovx decreases the formation of an Egr-1/Sp-1 protein-protein complex and increases the concentration of free Sp-1. Although we detected no Egr-1 binding to the putative Egr site of the M-CSF promoter, our data indicate that Egr-1 represses Sp-1induced M-CSF gene expression. To elucidate the mechanism of this phenomenon, increasing amounts of rEgr-1 were preincubated with SC nuclear extracts before the addition of radiolabeled Egr/Sp oligonucleotide. In each of three replicate experiments, a dose-dependent decrease in Sp-1 binding was observed (Fig. $3 A$ ) when Egr-1 was added to the reaction mixture. Levels of Egr-1 equal to $20 \mathrm{ng} /$ tube inhibited Sp-1 binding to the Sp site. In contrast, Egr-1 itself did not bind to the same sequence until its concentration reached $400 \mathrm{ng} /$ tube. The finding that concentrations of Egr-1 lower than those required for inducing a detectable Egr-1 band decrease Sp-1 binding suggests that Egr-1 modulates Sp-1 binding by a mechanism other than direct competition between the two transcription factors for binding to DNA. One such mechanism could be protein-protein interaction resulting in the formation of an Egr-1/Sp-1 complex possessing a lower affinity for the $\mathrm{M}-\mathrm{CSF}$ promoter than free Sp-1. Increased formation of the Egr-1/Sp-1 complex would result in decreased levels of free $\mathrm{Sp}-1$ available for binding to the Sp site. Conversely, decreased formation of Egr/Sp-1 complex would increase the availability of unbound Sp-1 as transcription factor.

To test whether Egr-1 and Sp-1 interact directly and if this interaction is modulated by $\mathrm{E} 2, \mathrm{SC}$ nuclear extracts were immunoprecipitated with an anti-Egr-1 antiserum. Western blots of immunoprecipitated material were then carried out using anti-Sp-1 antibody. In each of four experiments, the presence of a Sp-1/Egr-1 complex was observed (Fig. $3 B$ ) in nuclear extracts from all groups of mice, thus demonstrating the existence of a direct protein-protein interaction between Egr-1 and Sp-1. Importantly, densitometric analysis of the data from all experiments demonstrated that the Sp-1/Egr- 1 complex was $2.8 \pm 0.3$-fold less abundant in nuclear extracts from ovx mice (lane 3) than in those from either sham-operated (lane 2), E2treated ovx (lane 4), or IL-1ra and TNFbp-treated ovx mice (lane 5).

The occurrence of an Egr-1/Sp-1 interaction was confirmed by a reversed experiment in which SC extracts were immunoprecipitated by anti-Sp-1 antibody. The Sp-1/Egr-1 complex was then visualized by immunoblotting the recovered material with anti-Egr-1 antibody (not shown). This experiment demonstrated that only the 84-kD species of Egr-1 binds to Sp-1.

To test the specificity of the association, we generated a mutant Sp-1 in which the highly charged region, zinc finger region, and carboxyl terminal portions of Sp-1 were deleted. This truncation eliminates the 225 most carboxyl-terminal amino acids of the protein. This truncated form of Sp-1 (Sp$1 \Delta$ ) failed to bind to Egr-1 (Fig. $3 C$, lane 3), as compared with full-length Sp-1 (lane 2).

Since decreased formation of the Egr-1/Sp-1 complex without a change in total Sp-1 corresponds to increased $\mathrm{Sp}-1$ bind-
A

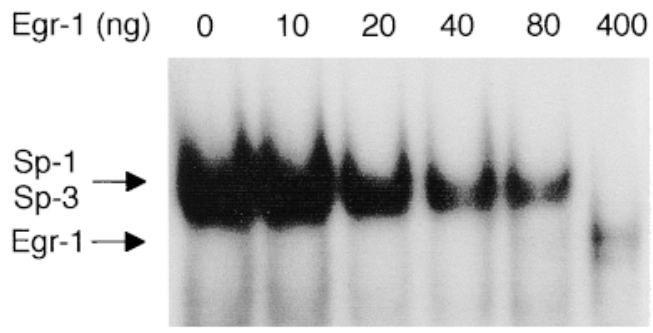

B

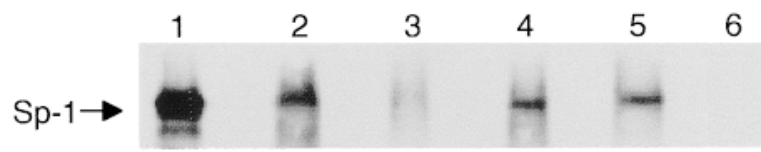

C

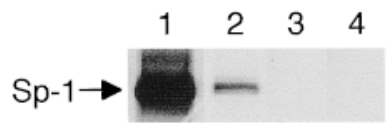

D

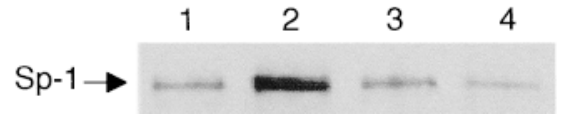

Figure 3. (A) Recombinant Egr-1 decreases the binding of endogenous Sp-1 and Sp-3 from the M-CSF promoter. EMSAs were performed by incubating increasing concentrations of rEgr-1 with IL-1and TNF-stimulated SC nuclear extracts from control mice for $20 \mathrm{~min}$ before the addition of a 26-bp radiolabeled oligonucleotide containing the $\mathrm{Egr} / \mathrm{Sp}$ binding site of the M-CSF promoter. Representative data from one of three replicate experiments. $(B)$ ovx decreases the formation of an Egr-1/Sp-1 complex. Nuclear extracts of IL-1- and TNF-stimulated SC were immunoprecipitated with anti-Egr-1 antiserum and blotted onto a nitrocellulose membrane. Sp-1 was then detected using anti-Sp-1 antiserum and chemiluminescence. Lane 1, Sp-1 control. Lane 2, sham-operated. Lane 3, untreated ovx. Lane 4, E2-treated ovx. Lane 5, IL-1ra + TNFbp-treated ovx. Lane 6, normal rabbit serum (negative control). Representative data from one of four replicate experiments. Densitometric analysis of the data from all four experiments revealed that the Egr-1/Sp-1 complex was 2.8 \pm 0.3 -fold lower in SC from ovx than in those from E2-replete mice. $(C)$ Truncated Sp-1 fails to associate with Egr-1. To demonstrate the specificity of the Sp-1/Egr-1 association, full-length (lane 2) and carboxyl-terminal truncated Sp-1 (lane 3) were in vitro transcribed/translated with radiolabeled $\left[{ }^{35} \mathrm{~S}\right]$ methionine and incubated with His-tagged Egr-1 coupled to agarose beads. After binding and extensive washing, Egr-1/Sp-1 complexes were resolved by SDS$\mathrm{PAGE}$, and the presence of $\mathrm{Sp}-1$ was detected by autoradiography. Lane 1 shows control radiolabeled Sp- 1 and lane 4 shows negative vector control. Identical results were obtained in each of three replicate experiments. $(D)$ Increased levels of free Sp-1 in SC nuclear extracts from ovx mice. To quantify the nuclear concentration of free Sp-1, SC nuclear extracts were immunoprecipitated with anti-Egr-1 antibody. This procedure was followed by a second IP with anti-Sp-1 antibody and Western blot analysis with anti-Sp-1 antibody. Lane 1, sham-operated. Lane 2, untreated ovx. Lane 3, E2-treated ovx. Lane 4, IL-1ra + TNFbp-treated ovx. Representative data from one of four replicate experiments. Densitometric analysis of the data from all four experiments revealed that the free Sp-1 levels were 3.2 \pm 0.5 fold higher in SC from ovx than in those from E2-replete mice. 
Table I. Evaluation of Egr-1/Sp-1 Association Using the Yeast 2-Hybrid Assay

\begin{tabular}{lcccc}
\hline \multicolumn{1}{c}{ Plasmid 1 } & Plasmid 2 & Color SFY526 & Growth HF7c & Color HF7c \\
\hline pGBT9-Sp-1 & - & White (negative) & (Negative) & $*$ White (negative) \\
pACT2-Egr-1 & - & White (negative) & (Negative) & $*$ White (negative) \\
pGBT9-Sp-1 & pACT2-Egr-1 & Blue (positive) & (Positive) & Blue (positive) \\
pLAM5' & pTD1 & White (negative) & (Negative) & $*$ White (negative) \\
pVA3 & pTD1 & Blue (positive) & (Positive) & Blue (positive) \\
\hline
\end{tabular}

Protein-protein interactions for Sp-1 (pGBT9-Sp-1) and Egr-1 (pACT2-Egr-1) were scored on the basis of lacZ activity, in host strain SFY526, in the presence of X-gal (blue color $=$ positive, white color $=$ negative), as well as by growth selection on histidine-deficient media, using host strain HF7c. In growth selection experiments, negative results in HF7c were further evaluated for lacZ expression, by supplementation of histidine (indicated by an asterisk) in order to elicit colony growth. The plasmid combinations pLAM5' + pTD1 and pVA3 + pTD1 were used as negative and positive controls, respectively.

ing to the M-CSF promoter, these findings suggest that ovx increases the levels of Sp-1 available for binding to the M-CSF promoter, with a consequent enhancement of gene transcription. To quantify the nuclear concentration of free Sp-1, SC nuclear extracts were immunoprecipitated with anti-Egr-1 antibody (to remove the Egr-1/Sp-1 complex). Supernatants were reimmunoprecipitated with anti-Sp-1 antibody and Western blot analysis with anti-Sp-1 antibody was performed. Four replicate experiments demonstrated (Fig. $3 D$ ) that SC from ovx mice have higher $(3.2 \pm 0.5$-fold, $P<0.05)$ nuclear levels of free $\mathrm{Sp}-1$ than those from E2-replete mice.

To confirm that the association of Egr-1 and Sp-1 occurs in vivo, we made use of the yeast 2-hybrid assay (32-34). Egr-1 and Sp-1 cDNAs were subcloned into the yeast 2-hybrid vectors $\mathrm{pACT} 2$ and $\mathrm{pGBT} 9$, respectively, such that fusion proteins were generated in vivo with the GAL4 activating domain coupled to Egr-1 and the GAL4 DNA-binding domain coupled to $\mathrm{Sp}-1$. Each fusion vector was transfected individually (as a negative control) and in combination into each of two different reporter yeast strains (SFY526 and HF7c). These studies revealed (Table I) the existence of a positive interaction with three distinct reporter systems, thus providing a demonstration of Sp-1 and Egr-1 interaction in vivo.

ovx decreases the association of Egr-1 with Sp-1 and modulates $S p-1$ binding to DNA by increasing Egr-1 phosphorylation. E2 may regulate the formation of the Egr-1/Sp-1 complex by modulating the nuclear concentration of Egr-1 and/or by inducing posttranslational modification of Egr-1, resulting in increased affinity for Sp-1. To investigate these possibilities, nuclear levels of Egr-1 protein were analyzed by Western blotting. This analysis revealed (Fig. 4) the expression of previously described multiple forms of Egr-1, a truncated, nonphosphorylated form of Egr-1 at $54 \mathrm{kD}$, and a 84-kD species which exhibits variable degrees of phosphorylation (35). Densitometric analysis of the data from four experiments revealed that nuclear extracts from ovx mice (lane 2 ) had 3.1 \pm 0.2 -fold higher $(P<0.05)$ amounts of the $84-\mathrm{kD}$ Egr-1 species than nuclear extracts from either sham-operated (lane 1) or ovx mice treated with either E2 (lane 3) or IL-1ra + TNFbp (lane 4). SC from ovx mice also exhibited slightly higher levels $(1.6 \pm 04-$ fold, $P=\mathrm{NS}$ ) of the $54-\mathrm{kD}$ form of Egr-1 than those from E2replete mice.

When the same nuclear extracts were analyzed again using an anti-Sp-1 antibody, in accordance with the data shown in Fig. 4 , we found equal levels of Sp-1 in all samples (not shown), confirming the specificity of the regulatory effects of E2 on Egr-1.
The closely spaced bands at $84 \mathrm{kD}$ represent multiple species which differ in their state of phosphorylation (35). Thus, our findings suggest that ovx increases the nuclear concentrations of phosphorylated forms of Egr-1, via a mechanism involving IL-1 and TNF.

To investigate the role of Egr-1 phosphorylation in regulating the formation of the Egr-1/Sp-1 complex, three replicate experiments were conducted in which SC nuclear extracts were incubated with calf intestinal alkaline phosphatase (CIAP) in the presence or absence of phosphatase inhibitors $\mathrm{NaF}, \mathrm{Na}_{4} \mathrm{P}_{2} \mathrm{O}_{7}$, and $\mathrm{NaVO}_{4}(35)$.

The representative results shown in Fig. $5 \mathrm{~A}$ demonstrate that treatment with CIAP decreased $84-\mathrm{kD}$ Egr-1 levels in samples from ovx mice (middle, lane 2), thus confirming the presence of phosphorylated Egr-1 in SC nuclear extracts. In contrast, CIAP treatment did not alter the levels of 54-kD Egr-1 (not shown). In samples from ovx mice, CIAP treatment also upregulated the levels of Egr-1/Sp-1 complex (Fig. 5 B, middle, lane 2) and downregulated Sp-1 binding to the M-CSF promoter (Fig. $5 C$, middle, lane 2). Attesting to the specificity of this process, the alterations in $84-\mathrm{kD}$ Egr-1, Egr-1/Sp-1 complex, and Sp-1 binding to DNA generated by CIAP were blunted by the simultaneous presence of phosphatase inhibitors (right panels, lane 2). Similar results were obtained in each of the three experiments. Taken together, the data suggest that E2 regulates the association of Sp-1 with Egr-1 and the resulting binding of free $\mathrm{Sp}-1$ to the M-CSF promoter by modulating Egr-1 phosphorylation.

ovx increases CKII activity resulting in increased phosphorylation of Egr-1. Since CKII is known to phosphorylate Egr-1 in fibroblasts (15), we investigated whether SC from ovx mice

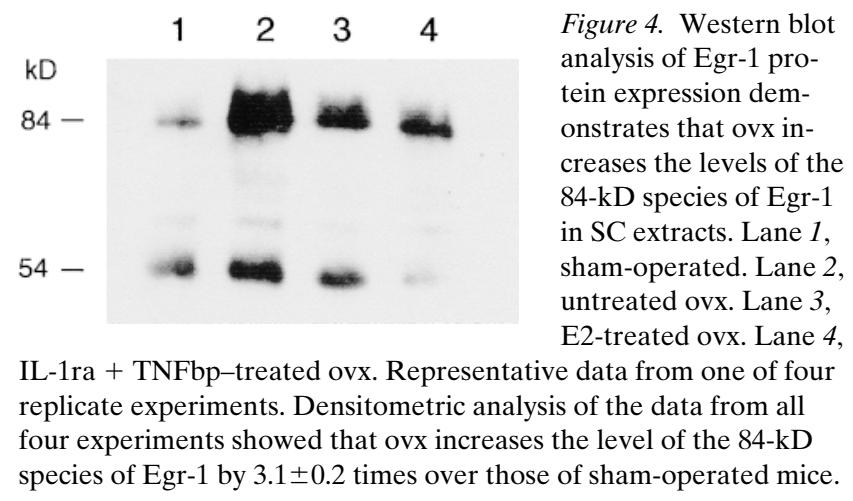


A

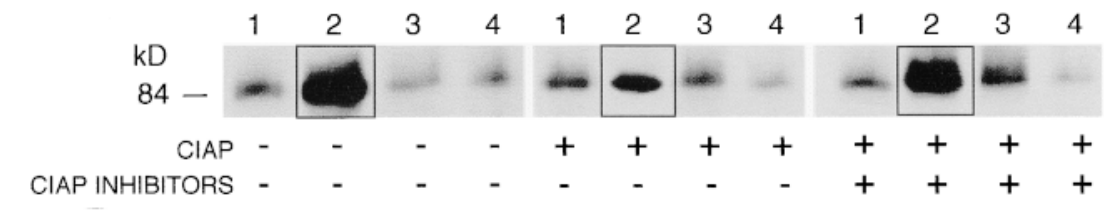

Figure 5. Alkaline phosphatase treatment of SC nuclear extracts decreases the levels of the phosphorylated 84-kD form of Egr-1 $(A)$, prevents the ovx-induced decrease in Egr-1/Sp-1 complex formation $(B)$, and blocks the increase in $\mathrm{Sp}-1$ binding to the

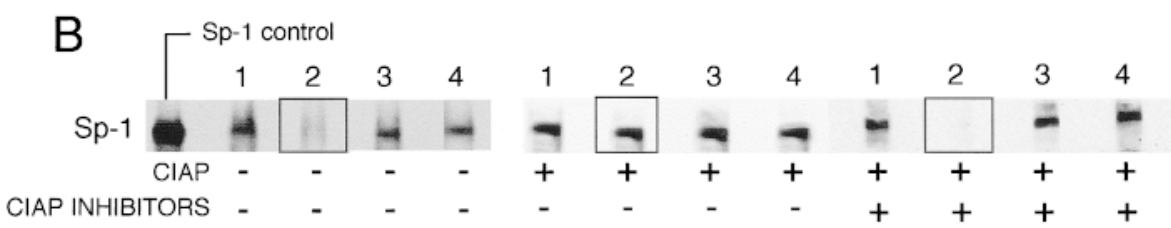
Sp site induced by ovx $(C)$. Representative data from one of three replicate experiments. SC nuclear proteins were extracted from sham (lane 1), ovx (lane 2), E2treated ovx (lane 3), and IL-1ra and TNFbp-treated ovx mice (lane 4). Samples were treated with or without CIAP, in the presence or absence of alkaline phos-
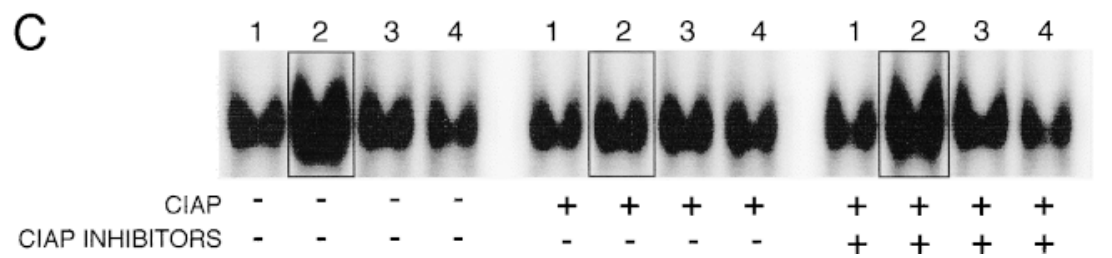

phatase inhibitors, as indicated. Egr-1 levels were measured by Western blot analysis as shown in Fig. 4. Egr-1/Sp-1 complex formation was determined as described in Fig. 3. Sp-1 binding to DNA was assessed by EMSA as described in Fig. 2. Boxes denote samples from ovx mice.

are characterized by increased CKII-induced Egr-1 phosphorylation. Thus, SC nuclear extracts were incubated with Egr-1 and $\left[\gamma^{-32} \mathrm{P}\right] \mathrm{ATP}$ in the presence and absence of heparin, a specific inhibitor of CKII (36). Phosphorylated material was spotted onto P81 paper and radioactivity was counted. These studies revealed that SC extracts from ovx mice induce higher Egr-1 phosphorylation than those from E2-replete mice (Fig. $6 \mathrm{~A}$, panel $a$ ). Addition of heparin to the reaction mixture abolished the difference between the groups, thus demonstrating that the higher phosphorylation of Egr-1 characteristic of SC from ovx mice was induced by CKII. It should be noted that heparin did not completely block the phosphorylation of Egr-1. Thus, mechanisms other than CKII activation are also capable of basal (i.e., non-ovx-related) Egr-1 phosphorylation. To further demonstrate that the increase in Egr-1 phosphorylation observed in SC from ovx mice is mediated by CKII, we took advantage of the ability of CKII to use GTP as a phosphate donor (16). Thus, SC were incubated with rEgr-1 and $[\gamma-$ ${ }^{32} \mathrm{P}$ ]GTP. We again found (Fig. $6 \mathrm{~A}$, panel $b$ ) that Egr-1 phosphorylation was higher in SC from ovx mice than in those from E2-replete mice. Egr-1 phosphorylation was completely blocked by heparin, thus demonstrating that CKII is the only kinase present in SC extract capable of phosphorylating Egr-1 using GTP as a source of phosphate.

To further demonstrate that increased Egr-1 phosphorylation observed in SC from ovx mice was the product of increased CKII activity, SC extracts were incubated with the specific CKII substrate peptide RRREEETEEE (36) and $[\gamma$ $\left.{ }^{32} \mathrm{P}\right] \mathrm{ATP}$. This CKII assay confirmed that SC from ovx mice have a higher CKII activity than SC from E2-replete mice (Fig. $6 \mathrm{~A}$, panel $c$ ). To conclusively determine that CKII activity is increased in SC from ovx mice, SC extracts were immunoprecipitated using anti-CKII $\alpha$ antiserum. The immunocomplexes were recovered and incubated with RRREEETEEE and $[\gamma-$ ${ }^{32} \mathrm{P}$ ]ATP to measure CKII activity. Analysis of the data from four experiments (Fig. $6 A$, panel $d$ ) showed that CKII activity was approximately sevenfold higher in SC from ovx mice than in those from sham and ovx E2-treated mice. Attesting to the specificity of the reaction, CKII activity was blocked by heparin in all groups.
CKII phosphorylates Egr-1 in vitro and decreases the binding of Egr-1 to Sp-1. Our data suggest that CKII-dependent phosphorylation of Egr-1 decreases the affinity of Egr-1 for Sp-1. To investigate this hypothesis, Egr-1 was phosphorylated in vitro by either CKII or protein kinase $\mathrm{C}$ (PKC) and incubated with Sp-1. The Egr-1/Sp-1 complex was then quantitated by IP with anti-Egr-1 antibody followed by immunoblotting with anti-Sp-1 antibody. In three such experiments, we found that Egr-1 is phosphorylated in vitro by both CKII and PKC (Fig. $6 B$, panel $a$ ). Moreover, incubation of dephosphorylated Egr-1 with Sp-1 resulted in the formation of an Egr-1/Sp-1 complex (Fig. $6 B$, panel $b$, lane 2). Conversely, when the same experiment was repeated using CKII phosphorylated Egr-1, there was no Egr-1/Sp-1 complex formation (Fig. $6 B$, panel $b$, lane 3). Attesting to the specificity of this reaction, phosphorylation of Egr-1 by PKC failed to inhibit Egr-1/Sp-1 complex formation (Fig. $6 \mathrm{~B}$, panel $b$, lane 4 ).

E2 replacement fails to block $M$-CSF production in Egr-1deficient mice. Our findings demonstrate that E2 regulates M-CSF production via a mechanism involving Egr-1. Thus, since M-CSF is critical for murine osteoclastogenesis, E2 should be unable to block SC secretion of M-CSF and OC formation in Egr-1-deficient mice.

To test this hypothesis Egr-1 KO mice and age-matched WT control littermates of the same genetic background were ovx at the age of $5 \mathrm{wk}$, treated with either vehicle or $17 \beta$ estradiol for $2 \mathrm{wk}$, and then killed. SC purified from bone marrow cells harvested at time of killing were cultured to confluence, stimulated with IL-1 and TNF for $4 \mathrm{~h}$, and then used to assess the expression of M-CSF mRNA by RNase protection assay. A second aliquot of unpurified bone marrow cells was cultured for $7 \mathrm{~d}$ in the presence of $1,25(\mathrm{OH})_{2} \mathrm{D}_{3}$ to induce the formation of OC $(9,17,37)$. This model was selected because the effects of ovx and E2 replacement on OC formation in cultures of bone marrow cells accurately reflect those induced in the number of OC adhering to bone surfaces in vivo (37).

Densitometric analysis of samples from WT mice revealed (Fig. $7 A$ ) that M-CSF mRNA expression was $2.1 \pm 0.3$-fold higher in SC from untreated ovx mice than in those from E2treated ovx mice. Conversely, analysis of samples from Egr-1 
A

จ NO HEPARIN
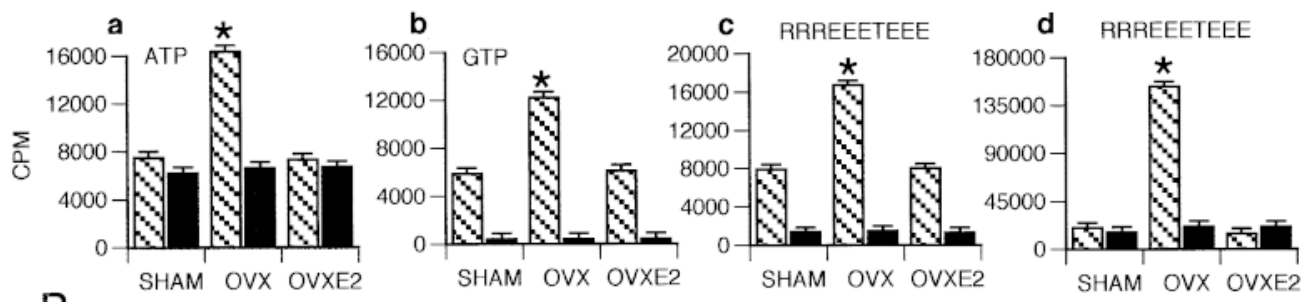

a

b

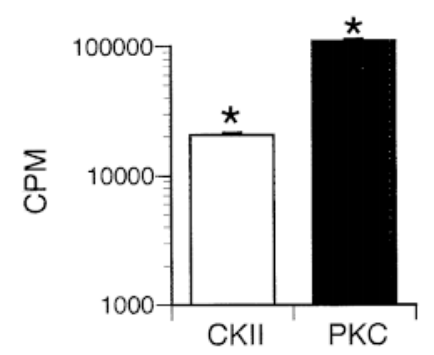

Figure 6. (A) Increased CKIIinduced phosphorylation of Egr-1 (panels $a$ and $b$ ) and increased CKII activity in SC from ovx mice (panels $c$ and $d$ ). SC were stimulated with IL-1 and TNF for $1 \mathrm{~h}$. Nuclear extracts were then incubated with Egr-1 and either $\left[\gamma^{32} \mathrm{P}\right]$ ATP (panel $\left.a\right)$ or $\left[\gamma^{-}{ }^{32} \mathrm{P}\right] \mathrm{GTP}$ (panel $b$ ) in the presence and absence of heparin. Phosphorylated material was spotted onto P81 paper and counted by liquid scintillation. Counts obtained in the absence of substrate were subtracted as background. To measure CKII activity, SC extracts were incubated with the specific CKII substrate RRREEETEEE and $\left[\gamma^{-32} \mathrm{P}\right] \mathrm{ATP}($ panel $c)$. To measure CKII activity in the absence of nuclear cofactors, SC extracts were immunoprecipitated by anti-CKII $\alpha$ antibody (panel $d$ ). The immunocomplexes were re-

covered by incubation with protein A-Sepharose $4 \mathrm{~B}$ beads and kinase activity was measured by incubation with RRREEETEEE and $\left[\gamma^{32} \mathrm{P}\right] \mathrm{ATP}$. Data shown represent the average of four replicate experiments. (B) Panel $a$ shows CKII- and PKC-induced phosphorylation of Egr-1 in vitro. rEgr-1 was incubated with either CKII or PKC and [ $\left.\gamma^{-32} \mathrm{P}\right]$ ATP to induce Egr-1 phosphorylation. Controls consisted of assays done in the absence of kinase and the counts so obtained were subtracted as background. Data shown represent the average of three replicate experiments. Panel $b$ shows that phosphorylation of Egr-1 by CKII but not by PKC blocks Egr-1/Sp-1 complex formation. Sp-1 was incubated with either dephosphorylated Egr-1 (lane 2), CKII phosphorylated Egr-1 (lane 3), or PKC phosphorylated Egr-1 (lane 4). The mixture was then immunoprecipitated by either anti-Sp-1 antibody (lane 1, control) or anti-Egr-1 antiserum (lanes 2-4) and then immunoblotted with anti-Sp-1 antiserum. Representative data from one of three replicate experiments.

$\mathrm{KO}$ mice revealed that SC from untreated ovx and E2-treated ovx mice exhibited no difference in the expression of M-CSF mRNA. These findings demonstrate that in vivo E2 blocks M-CSF mRNA expression via an Egr-1-dependent mechanism. In agreement with the essential role of M-CSF in murine osteoclastogenesis, we also found (Fig. 7 B) a larger number of OC in cultures of bone marrow cells from untreated ovx WT mice than in those from WT mice treated with E2. Conversely, in $\mathrm{KO}$ mice, OC number was increased in cultures from both E2-deficient and E2-replete mice, thus demonstrating that E2 fails to downregulate OC formation in Egr-1-deficient mice. Together, these data support the hypothesis that Egr-1 is a key regulator of the SC ability to produce $\mathrm{M}-\mathrm{CSF}$ and induce $\mathrm{OC}$ formation in vivo.

\section{Discussion}

This study was conducted to investigate the mechanism by which E2 deficiency increases IL-1- and TNF-induced production of M-CSF in SC (9). Promoter deletion studies in transiently transfected SC revealed that the Egr and Sp sites on the M-CSF promoter are critical for M-CSF gene expression. Moreover, cotransfections of SL-2 cells with Egr and Sp expression vectors showed that binding of Sp-1 to this site enhances M-CSF gene expression. Consistent with the functional relevance of Sp-1 and the Sp site in the regulation of the M-CSF gene, we found that SC from ovx mice, when stimulated with IL-1 and TNF, are characterized by enhanced M-CSF gene ex- pression as a consequence of augmented binding of Sp-1 to the Sp site on the M-CSF promoter. This enhanced binding results from increased CKII activation, an event which in turn leads to enhanced Egr-1 phosphorylation, and a resulting decreased formation of an Egr-1/Sp-1 complex. These events culminate in increased availability of unbound Sp-1 as a transcription initiator, without changes in total Sp-1 levels.

Overlapping consensus sequences for Egr-1 and members of the Sp transcription factor family have been described in the regulatory elements of numerous cytokine genes, including M-CSF (10), IL-2 (38), and TNF (39). Similar consensus sequences have been described in other genes unrelated to cytokine production $(40,41)$. Competition for DNA binding between the inducible product of the Egr-1 gene and the constitutively produced Sp-1 and/or other Sp family members provides a well defined means of transcriptional regulation $(38,39,42)$. Such a mechanism could account, at least in part, for the regulation of Sp-1 binding to the M-CSF promoter in SC. However, our studies revealed that binding of endogenous Egr-1 to the Egr site does not occur. However, Egr-1/DNA interactions can be induced when high concentrations of rEgr-1 are used. Thus, our findings argue against a competition between Sp-1 and Egr-1 for binding to overlapping consensus sequences in the Egr/Sp region of the M-CSF promoter. Our data are in agreement with the findings of Harrington et al. (42), who reported binding of high concentrations of Egr-1 but not of endogenous concentrations of nuclear Egr-1 to the Egr site on the M-CSF promoter. We attribute the inability of endogenous concentrations of Egr-1 to bind to the Egr site on 
A

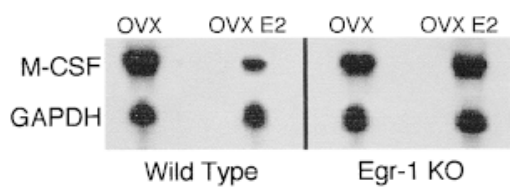

B

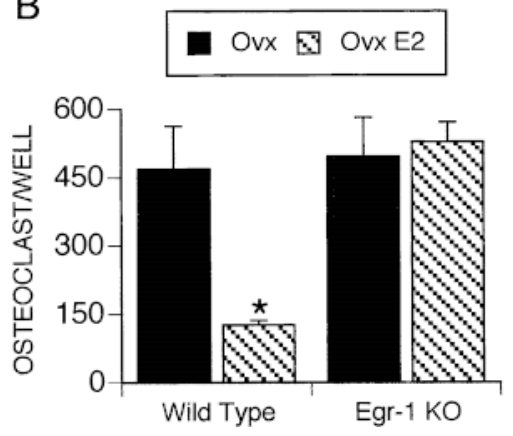

Figure 7. In vivo E2 replacement fails to decrease M-CSF mRNA expression in purified $\mathrm{SC}(A)$ and to block OC formation in cultures of bone marrow cells $(B)$ from ovx Egr-1 KO mice. WT and Egr-1 KO mice ( $n=5$ per group) were ovx and treated with either vehicle or E2 for 2 wk before time of killing. SC purified from bone marrow cells harvested at time of killing were cultured to confluence and then stimulated with IL-1 and TNF for $4 \mathrm{~h}$. M-CSF and GAPDH

mRNA expression was evaluated in three replicate assays by RNase protection assay. Densitometric analysis of the data from all assays demonstrated that in vivo E2 replacement decreases M-CSF mRNA levels by $2.1 \pm 0.3$-fold $(P<0.05)$ in Egr-1 KO but not in WT mice. $\mathrm{OC}$ formation was assessed in quadruplicate samples in cultures of bone marrow cells cultured for $7 \mathrm{~d}$ in the presence of $1,25(\mathrm{OH})_{2} \mathrm{D}_{3}$. $* P<0.05$ compared with untreated ovx mice.

the M-CSF promoter to the existence of an imperfect match (eight nucleotides out of nine) in the Egr-1 consensus DNAbinding sequence $(10,42)$. Indeed, an identical base mismatch has been shown to decrease by 100-fold the binding affinity of Egr-1 for the Egr/Sp site in the rat phenylethanolamine $N$-methyltransferase gene (43).

Our data demonstrate that in SC Egr-1 binds directly to Sp-1 and that this association is regulated by E2 via modulation of Egr-1 phosphorylation. Since Sp-1 is a general transcription activator, it is likely that inhibition of Egr-1 phosphorylation and the resulting sequestration of Sp- 1 may account for the ability of E2 to repress not only M-CSF, but also other genes that, like M-CSF, are induced by Sp-1. Deletion of the carboxyl terminus of Sp-1 containing the DNA-binding zinc finger region resulted in complete loss of association of this nuclear protein with Egr-1. These findings suggest that Egr-1 may suppress Sp-1-induced transcription by association at or near the Sp-1 zinc finger, thus perturbing its association with DNA. To the best of our knowledge, regulation of nuclear levels of free Sp-1 resulting from modulation of Egr-1/Sp-1 association has not been reported previously. Thus, the data describe a novel mechanism by which Egr-1 and Sp-1 regulate gene expression.

Whether the Egr-1/Sp-1 complex is also capable of binding to the M-CSF promoter remains to be determined. However, this is unlikely because no evidence for such a complex was detected in our EMSA studies. Also unlikely is the possibility that Egr-1/Sp-1 association may occur only in the context of binding of both proteins to DNA. In fact, formation of the Egr-1/Sp-1 complex was detected both in vitro in the absence of DNA and in the yeast 2-hybrid assay.

We also demonstrate that SC from E2-deficient mice are characterized by upregulated CKII activity and enhanced CKII-induced phosphorylation of Egr-1. Although in vitro
Egr-1 is phosphorylated by both CKII and PKC, in vitro association of Egr-1 and Sp-1 was blocked by phosphorylation of Egr-1 by CKII but not by PKC. Thus, it is likely that conformational changes of Egr-1 induced by phosphorylation of specific domains modulate the affinity of Egr-1 for Sp-1. Alternatively, the presence of phosphate group(s) in the Sp-1 binding region of Egr-1 may directly impede its association with Sp-1.

The mechanism by which acute IL-1 and TNF stimulation induces lower CKII activity in SC from E2-replete mice as compared with those from ovx mice remains to be examined. It is possible that E2 induces the formation of SC characterized by low expression of the signaling type I IL-1 or TNF receptors or high expression of the decoy type II receptors $(44,45)$. Such an effect of E2 on the expression of IL-1 type I and type II receptors has been described recently in OC (46).

Regardless of the specific mechanism, the different responses to acute IL-1 and TNF stimulation between SC from E2-replete and E2-depleted mice described in this study reflect events induced by $\mathrm{E} 2$ depletion in vivo, such as the differentiation of SC precursors in the bone marrow microenvironment (9). ovx is known to increase bone marrow concentrations of IL-1 and TNF $(9,17,47)$. Moreover, we have now found that in vivo treatment with either IL-1ra plus TNFbp or E2 is equally capable of preventing the effects of ovx on M-CSF gene expression, Sp-1 binding to DNA, Egr-1/Sp-1 complex formation, Egr-1 phosphorylation, and CKII activation. Thus, the data demonstrate that long-term exposure to increased bone marrow levels of IL-1 and TNF is required for maturing $\mathrm{SC}$ to acquire the capacity of producing increased amounts of M-CSF in response to acute IL-1 and TNF stimulation (9). Furthermore, since M-CSF is critical for murine osteoclastogenesis $(3,4)$, and the functional block of IL-1 and TNF with IL-1ra and TNFbp also prevents the ovx-induced bone loss $(47,48)$ and increase in OC formation $(17)$, the data also explain how IL-1 and TNF mediate the postmenopausal increase in bone resorption.

Taken together, the findings of this study demonstrate that Egr-1 is a key mediator of the effects of E2 on M-CSF gene expression in SC, and the resulting regulation of osteoclastogenesis. The relevance of Egr-1 to the mechanism by which E2 blocks OC formation in vivo was confirmed by examining both the expression of M-CSF mRNA in purified SC and the production of OC by cultures of bone marrow cells from Egr-1 KO mice (18). Macroscopically, these mice do not exhibit a skeletal phenotype, indicating that Egr-1 is not essential for normal bone modeling. However, Egr-1 deficiency blocks the ability of E2 to repress M-CSF mRNA expression and confers on bone marrow cells a complete resistance to in vivo E2 treatment, leading to the emergence of a highly osteoclastogenic bone marrow microenvironment.

In summary, E2 deficiency, via an IL-1- and TNF-mediated mechanism, decreases association between Egr-1 and Sp-1 in SC nuclei. This phenomenon is a consequence of increased CKII activation and CKII-induced Egr-1 phosphorylation and results in increased levels of free Sp-1 available for binding to, and transactivation of, the M-CSF promoter.

\section{Acknowledgments}

This study was supported in part by grants from the National Institutes of Health (AR 41412 and AG 13534). 


\section{References}

1. Manolagas, S.C., and R.L. Jilka. 1995. Bone marrow, cytokines, and bone remodeling. N. Engl. J. Med. 332:305-311.

2. Roodman, G.D. 1996. Advances in bone biology: the osteoclast. Endocr. Rev. 17:308-332.

3. Tanaka, S., N. Takahashi, N. Udagawa, T. Tamura, T. Akatsu, E.R. Stanley, T. Kurokawa, and T. Suda. 1993. Macrophage colony-stimulating factor is indispensable for both proliferation and differentiation of osteoclast progenitors. J. Clin. Invest. 91:257-263.

4. Yoshida, H.S., S. Hayashi, T. Kunisada, M. Ogawa, S. Nishikawa, H. Okamura, T. Sudo, and L.D. Schultz. 1990. The murine mutation osteopetrosis is in the coding region of macrophage colony stimulating factor gene. Nature. 345:442-444.

5. Sarma, U., and A.M. Flanagan. 1996. Macrophage colony-stimulating factor induces substantial osteoclast generation and bone resorption in human bone marrow cultures. Blood. 88:2531-2540.

6. Sherman, M.L., B.L. Weber, R. Datta, and D.W. Kufe. 1990. Transcriptional and posttranscriptional regulation of macrophage-specific colony stimulating factor gene expression by tumor necrosis factor. J. Clin. Invest. 85:442447.

7. Falkenburg, J.H., M.A. Harrington, R.A. de Paus, W.K. Walsh, R. Daub, J.E. Landegent, and H.E. Broxmeyer. 1991. Differential transcriptional and posttranscriptional regulation of gene expression of the colony-stimulating factors by interleukin-1 and fetal bovine serum in murine fibroblasts. Blood. 78: 658-665.

8. Pfeilschifter, J., C. Chenu, A. Bird, G.R. Mundy, and G.D. Roodman. 1989. Interleukin-1 and tumor necrosis factor stimulate the formation of human osteoclast-like cells in vitro. J. Bone Miner. Res. 4:113-118.

9. Kimble, R.B., S. Srivastava, F.P. Ross, A. Matayoshi, and R. Pacifici. 1996. Estrogen deficiency increases the ability of stromal cells to support osteoclastogenesis via an IL-1 and TNF mediated stimulation of M-CSF production. J. Biol. Chem. 271:28890-28897.

10. Harrington, M.A., H.J. Edenberg, S. Saxman, L.M. Pedigo, R. Daub, and H.E. Broxmeyer. 1991. Cloning and characterization of the murine promoter for the colony-stimulating factor-1-encoding gene. Gene. 102:165-170.

11. Cao, X.M., R.A. Koski, A. Gashler, M. McKiernan, C.F. Morris, R. Gaffney, R.V. Hay, and V.P. Sukhatme. 1990. Identification and characterization of the Egr-1 gene product, a DNA-binding zinc finger protein induced by differentiation and growth signals. Mol. Cell. Biol. 10:1931-1939.

12. Milbrandt, J. 1987. A nerve growth factor-induced gene encodes a possible transcriptionally regulated factor. Science. 238:797-799.

13. Kadonaga, J.T., K.R. Carner, F.R. Masiarz, and R. Tjian. 1987. Isolation of cDNA encoding transcription factor Sp1 and functional analysis of the DNA binding domain. Cell. 51:1079-1090.

14. Hagen, G., S. Muller, M. Beato, and G. Suske. 1994. Sp1-mediated transcriptional activation is repressed by Sp3. EMBO (Eur. Mol. Biol. Organ.) J. 13: 3843-3851.

15. Jain, N., R. Mahendran, R. Philp, G.R. Guy, Y.H. Tan, and X. Cao. 1996. Casein kinase II associates with Egr-1 and acts as a negative modulator of its DNA binding and transcription activities in NIH 3 T3 cells. J. Biol. Chem. 271:13530-13536.

16. Allende, J.E., and C.C. Allende. 1995. Protein kinase CK2: an enzyme with multiple substrates and a puzzling regulation. FASEB (Fed. Am. Soc. Exp. Biol.) J. 9:313-323.

17. Kitazawa, R., R.B. Kimble, J.L. Vannice, V.T. Kung, and R. Pacifici. 1994. Interleukin-1 receptor antagonist and tumor necrosis factor binding protein decrease osteoclast formation and bone resorption in ovariectomized mice. J. Clin. Invest. 94:2397-2406.

18. Lee, S.L., L.C. Tourtellotte, R.L. Wesselschmidt, and J. Milbrandt. 1995. Growth and differentiation proceeds normally in cells deficient in the immediate early gene NGFI-A. J. Biol. Chem. 270:9971-9977.

19. Lee, S.L., Y. Sadovsky, A.H. Swirnoff, J.A. Polish, P. Goda, G. Gavrilina, and J. Milbrandt. 1996. Luteinizing hormone deficiency and female infertility in mice lacking the transcription factor NGFI-A (Egr-1). Science. 273: 1219-1221.

20. Sambrook, J., E.F. Fritsch, and T. Maniatis. 1989. Molecular Cloning: A Laboratory Manual. Cold Spring Harbor Laboratory, Cold Spring, Harbor, NY.

21. Godambe, S.A., D.D. Chaplin, T. Takora, L.M. Read, and C.J. Bellone. 1995. A novel cis-acting element for lipopolysaccharide induced transcription of the murine interleukin-1 $\beta$ gene. Mol. Cell. Biol. 15:112-119.

22. Hall, C.V., P.E. Jacob, G.M. Ringold, and F. Lee. 1983. Expression and regulation of Escherichia coli Lac Z fusion in mammalian cells. J. Mol. Appl. Genet. 2:101-109.

23. Schneider, I. 1972. Cell lines derived from late embryonic stages of
Drosophila melanogaster. J. Embryol. Exp. Morphol. 27:353-365.

24. Maniatis, T., S. Goodbourn, and J.A. Fischer. 1987. Regulation of inducible and tissue-specific gene expression. Science. 236:1237-1244.

25. Andrews, N.C., and D.V. Faller. 1991. A rapid micropreparation technique for extraction of DNA-binding proteins from limiting numbers of mammalian cells. Nucleic Acids Res. 19:2499.

26. Tetsuka, T., S.K. Srivastava, and A.R. Morrison. 1996. Tyrosine kinase inhibitors, genistein and herbimycin A, do not block interleukin-1 beta-induced activation of NF-kappa B in rat mesangial cells. Biochem. Biophys. Res. Commun. 218:808-812.

27. Towbin, H., T. Staehelin, and J. Gordon. 1979. Electrophoretic transfer of proteins from polyacrylamide gels to nitrocellulose sheets: procedure and some applications. Proc. Natl. Acad. Sci. USA. 76:4350-4354.

28. Walton, G.M., P.J. Bertics, L.G. Hudson, T.S. Vedvick, and G.N. Gill. 1987. A three-step purification procedure for protein kinase C: characterization of the purified enzyme. Anal. Biochem. 161:425-437.

29. Heller-Harrison, R.A., and M.P. Czech. 1991. Enhanced casein kinase II activity in COS-1 cells upon overexpression of either its catalytic or noncatalytic subunit. J. Biol. Chem. 266:14435-14439.

30. Chomcyznski, P., and N. Sacchi. 1987. Single-step method of RNA isolation by acid guanidinium-thiocyanate-phenol-chloroform extraction. Anal. Biochem. 162:156-159.

31. Courey, A.J., and R. Tjian. 1988. Analysis of Sp1 in vivo reveals multiple transcriptional domains, including a novel glutamine-rich activation motif. Cell. 55:887-898.

32. McNabb, D.S., and L. Guarente. 1996. Genetic and biochemical probes for protein-protein interactions. Curr. Opin. Biotechnol. 7:554-559.

33. Bai, C., and S.J. Elledge. 1996. Gene identification using the yeast twohybrid system. Methods Enzymol. 273:331-347.

34. Luban, J., and S.P. Goff. 1995. The yeast two-hybrid system for studying protein-protein interactions. Curr. Opin. Biotechnol. 6:59-64.

35. Day, M.L., T.J. Fahrner, S. Aykent, and J. Milbrandt. 1990. The zinc finger protein NGFI-A exists in both nuclear and cytoplasmic forms in nerve growth factor-stimulated PC12 cells. J. Biol. Chem. 265:15253-15260.

36. Kuenzel, E.A., and E.G. Krebs. 1985. A synthetic peptide substrate specific for casein kinase II. Proc. Natl. Acad. Sci. USA. 82:737-741.

37. Jilka, R.L., G. Hangoc, G. Girasole, G. Passeri, D.C. Williams, J.S Abrams, B. Boyce, H. Broxmeyer, and S.C. Manolagas. 1992. Increased osteoclast development after estrogen loss: mediation by interleukin-6. Science. 257: 88-91.

38. Skerka, C., E.L. Decker, and P.F. Zipfel. 1995. A regulatory element in the human interleukin 2 gene promoter is a binding site for the zinc finger proteins Sp1 and EGR-1. J. Biol. Chem. 270:22500-22506.

39. Kramer, B., A. Meichle, G. Hensel, P. Charnay, and M. Kronke. 1994 Characterization of an Krox-24/Egr-1-responsive element in the human tumor necrosis factor promoter. Biochim. Biophys. Acta. 1219:413-421.

40. Dennig, J., J. Hagen, M. Beato, and G. Suske. 1995. Members of the SP transcription factor family control transcription from the uterglobin promoter. J. Biol. Chem. 270:12737-12744.

41. Ackerman, S.L., A.G. Minden, T.G. Williams, C. Bobonis, and C.Y. Yeung. 1991. Functional significance of an overlapping consensus binding motif for Sp1 and Zif268 in the murine adenosine deaminase gene promoter. Proc. Natl. Acad. Sci. USA. 88:7523-7527.

42. Harrington, M.A., B. Konicek, A. Song, X. Xia, W.J. Fredericks, and F.J. Rauscher. 1993. Inhibition of colony-stimulating factor-1 promoter activity by the product of Wilm's tumor locus. J. Biol. Chem. 268:21271-21275.

43. Ebert, S.N., and D.L. Wong. 1995. Differential activation of the rat phenylethanolamine $N$-methyltransferase gene by Sp1 and Egr-1. J. Biol. Chem. 270:17299-17305.

44. Gruss, H.J., J. Duyster, and F. Herrmann. 1996. Structural and biological features of the TNF receptor and TNF ligand superfamilies: interactive signals in the pathobiology of Hodgkin's disease. Ann. Oncol. 7(Suppl. 4):19-26.

45. Martin, M.U., and W. Falk. 1997. The interleukin-1 receptor complex and interleukin-1 signal transduction. Eur. Cytokine Netw. 8:5-17.

46. Sunyer, T., J. Lewis, and P. Osdoby. 1997. Estrogen decreases the steady state levels of the IL-1 signaling receptor (type I) while increasing those of the IL-1 decoy receptor (type II) in human osteoclast-like cells. J. Bone Miner. Res. 12(Suppl. 1):131a.

47. Kimble, R.B., J.L. Vannice, D.C. Bloedow, R.C. Thompson, W. Hopfer, V. Kung, C. Brownfield, and R. Pacifici. 1994. Interleukin-1 receptor antagonist decreases bone loss and bone resorption in ovariectomized rats. J. Clin. Invest. 93:1959-1967.

48. Kimble, R.B., A.B. Matayoshi, J.L. Vannice, V.T. Kung, C. Williams, and R. Pacifici. 1995. Simultaneous block of interleukin 1 and tumor necrosis factor is required to completely prevent bone loss in the early post-ovariectomy period. Endocrinology. 136:3054-3061. 